\title{
Job Involvement - Sense of Participation - Job Satisfaction: A Triangular Framework
}

\author{
${ }^{1}$ Dr. Nazir Ahmad Gilkar, ${ }^{2}$ Javid Ahmad Darzi \\ ${ }^{1}$ Principal, Sri Pratap College, Srinagar \\ ${ }^{2}$ Faculty (contractual) Govt. Amar Singh College, Srinagar.
}

\begin{abstract}
The Job involvement concerns the degree to which employees identify themselves with their job. It may be influenced by the level of satisfaction of one's needs- intrinsic or extrinsic. The concept of participative management is considered as a mechanism where workers have a say in decision- making process of an organization. As a sequel to job involvement and participative management, job satisfaction increases productivity through bringing high quality motivation and through increasing working capabilities at the time of implementation. (Miller and Monge, 1986). The contextual analysis of the aforesaid three constructs is highlighted in the triangular framework in this paper.
\end{abstract}

\section{The context}

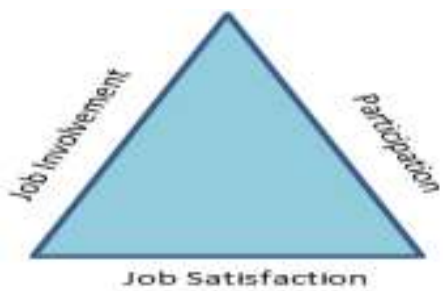

\section{Job Involvement}

The available research on job involvement is comparatively recent and done mostly by empirically orientedpsychologists. While there is a great deal of confusionregarding the concept of JI, Mckelvey andSekaran (1977) have aptly defined it as "the mergingof a person's ego identity with his or her job." It, thus, concerns the degree to which employees take their identity from their job. This definition follows that of Gurin, Veroff, and Feld (1960), who spoke of the extent to which individuals seek some expression and actualization of the self in their work, and that of Lodahl and Kejner (1965) who defined JI in terms of the degree to which people are identified psychologically with their workand the importance of work in the individual'sself-image. Rabinowitz and Hall(1977) also concluded from their evaluation of research on JI thatthe data are more consistent with this"psychological identification with work" definitionof JI than with the other definition (performanceself esteem contingency) provided byLodahl and Kejner.

The concept of JI has alsobeen the mainspring energizing the symbiotic relationshipbetween JI, performance, and the quality of working life, because individuals who havetheir ego development tied into the jobs have a higher stake in performing well and there is often a strong desire to satisfy the need for ego identityand development in their jobs Mckelvey and Sekaran (1977).In recent years, there have been spirited effortsthroughout the world by top echelons of managementto redesign jobs in order to increase JI. Thisis apparently based on the belief that JI is conduciveto both productivity and job satisfaction. According to Kanungo (1979), all behavior, includingbehavior in work situations, springs from needstates of the individual and is directed towards obtaining outcomes for the satisfaction of salientneeds. Thus, the degree of JI will depend upon theextent to which an individual perceives his salientneeds as capable-of being met on the job. Kanungo (1979), therefore, operationally defined JIas, "ageneralized cognitive state of psychologicalidentification with work, in so far as work isperceived to be instrumental in satisfying one's salient needs and expectations."Results of a recent study of over 200 middle and senior level managers by Misra and Kalro (1981) supported the notion that the attitude of JI is afunction of the level of satisfaction of one's salientneeds, be they intrinsic or extrinsic. JI was higherfor those whose salient needs were met as comparedwith those whose salient needs were not met. 


\section{Participative Management}

The view points of social scientists reflect that participative management is one of the tools of management where the emphasis is on the utility of human approach. The experiments of Blake, Mayo, Lewin and Likert (1963)popularized the belief that once workers are provided opportunities to participate in the management process lead to positive gains to the organizations' effectiveness and morale of employees which has its impact on satisfaction. The concept of participation may be defined as the mental and emotional involvement of a person in a group situation that encourages him to contribute to group goals and share responsibilities in them Davis (1957). Vroom (1960) has distinguished between psychological participation and objective participation. Psychological participation, according to him, refers to the amount of influence an individual perceives he has on decision- making, while objective participation refers to the amount of influence individual actually does have on decision- making. The former is perceptive in nature and the latter suggests impact.

According to Lammers (1967), participation in decision making is totality of such forms of upward exertion of power by subordinates in organizations as are perceived in this sense can be of two varieties, i.e. direct or indirect. Gardner (1977) has very aptly pointed out that participation incorporates two of the very strong social motives, namely, self respect and social approval. The former comes into play when the worker is doing a job which he understands and of which he approves. Participation as has been suggested by Mulder (1971), is the most vital organizational problem of overtime...For individual members, feeling of well being and their sense of self-realization are related to participation and its consequences. Vroom (1960) in an earlier study gathered evidence and suggested that the effect of participation in decision making on satisfaction depends on personality of the participants. The democratic participatory theory emphasizes on conditions that are necessary for effective participation and function performed by participation to the individuals and society. (Rosseau, 1956) contended that through participation in decision making, individual sense of freedom increased since it gives him a very real degree of control over the course of his life and structure of his environment. Again, it serves to increase the value of individual freedom by enabling him to be his own master. Mills (1965) visualized industry as an area where an individual could gain experience in the management of the collective just as he could in government.

The theory views that the political arenas as a kind of market place in which individuals constantly attempt to maximize the benefits minimize losses they could secure from the political process. Thus, each participant would be motivated by the desire to protect or enhance his own personal interest. That increased participation is likely to increase the feeling of political efficiency that ordinary citizens possess. This helps to increase the potential so that their actions can have effect on public policy and lead to a greater sense of control. In essence, greater participation in one sense of life leads to greater participation in other spheres i.e. the work place (Pateman, 1970).

The employee participation generally refers to a process in which influence is shared among individuals who are otherwise hierarchically unequal (Locke and Schweiger, 1979; Wagner, 1994). Participatory management practice balances the involvement of managers and their subordinates in information processing, decision- making and problem- solving endeavors Wagner (1994).The other line of enquiry on participatory management is focused on its impact on organizational outcomes such as organization performance and work outcomes including job satisfaction Rooney (1987), productivity (Rooney, 1987; Warneke and Levitan, 1994), product quality Cook( 1992), absenteeism Voos ( 1989) and employee and superior relations Cook ( 1990). Because of the different methodologies used in their studies, the results tend to be mixed (Wagner, 1994; Huang, 1997). Employee participation has been emphasized in relation to job satisfaction Cotton et al.,(1988). Past studies showed that employee participation is positively related to performance, satisfaction, and productivity of an employee (Wagner, 1994; Verma, 1995)

\section{Job satisfaction}

The job satisfaction increases productivity through bringing high quality motivation and through increasing working capabilities at the time of implementation (Miller and Monge: 1986). There is evidence that participative climate has a more substantial effect on workers' satisfaction than participation in specific decision and it appears that participation in goal setting has a strong effect on both job satisfaction and productivity. Human resource policies that encourage worker involvement aim at providing employees with opportunities to have an input in decisions, incentives to expend discretionary effort and the means to acquire the appropriate skills (Borg: 1999).The contextual analysis is further elaborated with due support of original thought and presented in annexure-I 


\begin{abstract}
III. The Study
Rationale

The triangular framework discussed above signifies its importance for productivity and work efficiency of an organization. It is in this backdrop that the present study has been attempted for contextual analysis.
\end{abstract}

\title{
Objective
}

The objective of the present study is to explore the possible influence of job involvement and sense of participation on job satisfaction in the context of a triangular framework.

\section{Methodology}

The present attempt primarily is a review article and is based on the available literature in the form of books and research papers. The contextual analysis is thus made in accordance with the preset objectives.

\section{Contextual Discussion Analysis}

The past studies on the subject reveal as under:

- The conceptualized job involvement as the degree to which total job satisfaction is a central life interest i.e.; the degree to which it is perceived to be a major source of satisfaction of important needs Dublin (1956, 1968). This contention is almost identical to that of Lawler and Hall (1970) who says it is the degree to which a person perceives his total work situation to be an important part of his life and to be central to him and his identity because of the opportunity it affords him to satisfy his important needs. Along the same lines, Lodhal and Kejner (1965)defined job involvement as the degree ones work in ones total life image and Guion (1958) proposed that it is characterized by the employee's perception of the jobs being of extreme importance. A number of tools have been used to measure the central life interest type of involvement for instance, a number of items in Lodhal and Kejner's (1965) job involvement (e.g. the most important things that happen to me involve my work. I live, eat and breathe my job).

- The participation of workers in management refers to the mental and emotional involvement of a person in a group situation which encourages him contributes to group goals and share in responsibility of achieving them (Keith Davis, 1959). Keeping in view the above argument Coch and French (1949) considered to be the pioneers in studying employee participation in the work place developed the productivity and participation rationale, assuming that there is a direct link between employee participation in decision- making and work outcomes such as the increase in job satisfaction and productivity. Participation in decision - making can satisfy employees self actualization needs and by doing so, increase employees motivation and job performance (Likert, 1961). The empirical evidence about the effects of employee participation is still emerging but the findings of Batt and Appelbaum (1995) based on a comparison of self managing work groups and traditionally managed groups are illustrative. They find a number of positive aspects of work in self managing teams, including greater job satisfaction, organizational commitment, autonomy, identity and meaning in work.The participation of employees is a managerial technique for involving employees in decision- making process. Participation is an interaction in which communication occurs among participants whereby a particular set of outcomes can occur. The manner of participation and the level at which it is exercised consequently brings forth outcomes such as organizational effectiveness, job satisfaction and job involvement (Pathak, 1983), Participation provides the employees a sense of importance, consultation and partnership in joint decision making. In this backdrop, an attempt has been made to study the relationship between participation and job satisfaction.

- The employees are more willing to get involved in decision-making, goal setting or problem solving activities which subsequently result in higher employee performance (Helliegel, Slocum and Woodman, 1998). Encouraging a more modern style of participatory management, inter alia, raises employee satisfaction. Participative climate has a more substantial effect on worker's satisfaction than participation in specific decisions and it appears that participation has a strong effect on job satisfaction. Human Resource policies that encourage worker involvement aimed at providing employees with opportunities to have an input in decisions, incentives to exercise discretionary effort and the means to acquire the appropriate skills (Berg, 1999).

The various dimensions of job satisfaction are discussed with due support of empirical investigations in detail hereunder:

\section{Job Concrete Area}

That both the categories of respondents strongly feel, if given a chance, they would put their children in the job that they are doing. This is probably more because of the tight job market conditions than job satisfaction. Their jobs easily give them time and opportunities to attend their families and their jobs have recreation and entertainment in good measure. Communication networks (both upward and downward) are sufficiently adequate. However, working conditions are slightly satisfactory and places of postings are inconvenient to them and their families. 


\section{Job Abstract Area}

That majority of the respondents seldom agree that their bosses and colleagues are cooperative, sincere, helpful and inspiring. They would seldom or under compulsion work on Sundays and holidays in the absence of overtime allowances. On the scale of democratic functioning they rate their jobs as slightly democratic and also rate their jobs at par with others with having moderate possibility of malpractices like corruption and favoritism. Moreover, given a chance to switch over to other jobs they would quickly move even if the emoluments don't register any enhancement.

\section{Psycho-social Area}

That different category of respondents view that the training, orientation and experience they got while on the job has improved their competence and efficiency owing to which their social circle has widened to their great advantage. Their jobs, to some extent, are responsible for developing in them desirable styles of life with regard to habits and attitudes and also there are moderate to very many opportunities for officiating, promotions and increased responsibilities. There is a feeling running throughout, as reflected here; they are performing the jobs for which they are superior in terms of intelligence, capacity, and diligence. Despite these advantages they feel that their social status is poor though the global feeling of being satisfied with the jobs remains there.

\section{Economic Area}

That various kinds of respondents exhibit lukewarm attitude towards the satisfaction of financial factors. With regard to salary and allowances they feel that their jobs are poorly satisfying though they are provided the facilities like medical care, housing, subsidized rationing and travelling etc. Moreover, their jobs have sufficient provision to offer jobs and ex-gratia grants to their dependents. Post retirement benefits are rated so-so.

\section{Community/National Growth Area}

That the jobs endeavor to make life better for the employees; agree to the view that their profession adds to the economy and development of the nation; to family and friends their jobs appear to be okay, however, opportunity to take side jobs are quite few. They also agree strongly to the view that their jobs leave no scope for freedom, decision making, initiative etc. rather it produces boredom. The dictum of 'work is worship' is not right in their case.

\section{Occupational level and Job Satisfaction}

Job satisfaction of employees has been reported to vary with the occupational level. Jobs which are high in level are generally better paid, less repetitive, provide more freedom and require less physical effort than other jobs lower in level. Besides other factors, opportunity of self expression, self actualization and salary are found to be the main aspects of occupational level.

\section{Conclusions and policy implications}

The present study comes forward with the following main findings:

- That majority of the respondents are of the view that their jobs are major life interest to them. They feel happy after completing some work. However, they find their jobs less interesting.

- That job satisfaction of high involved employees is higher than that of low involved ones in all the dimensions of job satisfaction i.e. 'job concrete', 'job abstract', 'psycho-social', 'economic' and community dimensions.

- That top line and bottom line groups showed maximum satisfaction with 'psycho-social' dimensions followed by 'community' and the least satisfaction was shown with 'economic' dimension. However, their perceptions differed with respect to 'job concrete' and 'job abstract dimensions'.

- That there is a close correspondence in the perceptions of employees with respect to their sense of participation .Employees are given the opportunity to serve on committees with supervisors .However their beliefs diverge with respect to freedom in experimenting their ideas.

- That Job satisfaction of high participation employees is higher than those of low participation employees on all the five dimensions of job satisfaction.

- That sense of participation positively affects employee job satisfaction. The study suggests that emphasizing participative management can enhance employee job satisfaction. In this regard, management's commitment to changing organizational culture from traditional patterns of hierarchical structure to participative management and empowering should be emphasized in the bank

- That enhanced participation will lead not only to better decisions but also will make the implementation of the decisions easier and more effective due to the perception of the group members that it is their decision. The employee, therefore, is very much personally affected by his whole situation i.e. the work itself. 
The employee job satisfaction is influenced by their job involvement. Management of the bank is desired to make significant efforts to ensure the employees are more involved in their jobs. This could be done by making jobs more interesting and enriched in design, less ambiguous, strenuous and monotonous and adequately rewarding. Organizational climate should also be made more congenial and supportive. Satisfaction of employees higher order needs may also help in enhancing their job involvement levels. The employees must be given authority, personal responsibility and freedom in performing their job roles. In this regard a few measures are suggested thus:

- To create a work place which is co-operative and where employees are cherished and wanted is essential for job satisfaction. This requirement is omnibus in many ways and includes the prevention of harassment, involvement of employees in real goal setting, planning and problem- solving.

- To show respect for diverse ideas and opinions, giving and taking honest and constructive feedback, arranging for mentoring facilities, and sharing as much information with employees as possible.

- To continuously work towards employee progression and advancement in skills and responsibilities, by way of using full range of employee knowledge and skills by providing opportunities for challenging assignments.

- To consider reassignments so that employee strengths align with position requirements, providing meaningful work with restructuring of positions if necessary and possible.

- To provide public recognition of efforts and achievements, giving employees additional responsibilities and the freedom to take action, explaining why assignments are important for the accomplishment.

- To provide opportunities to learn in new situations and support development assignments and on the job training. This knowledge would allow to management to spend their limited resources wisely to get the best benefit for the organization by having well satisfied work force.

- To allow employees to be involved in all the decisions that affect their jobs have a positive influence on their morale, satisfaction level and subsequent service quality.

- To offer as much amenities as possible to the employees to keep them contented. Such a philosophy must pervade across the entire organization.

- To recognize and reward relevant knowledge, expertise and extra efforts of the bank employees.

- To allow employees to be involved in all the decisions that affect their jobs will have a positive influence on their morale, satisfaction level and subsequent service quality.

- To provide as much amenities as possible to the employees to keep them contended. Such a philosophy must pervade in all the branches of the bank.

- To initiate steps to identify and recognize and reward relevant knowledge, expertise and extra efforts of the bank employees.

\section{Annexure-I}

- Maslow (1954) suggested that human needs form a five-level hierarchy ranging from physiological needs, safety, belongingness and love, esteem to self-actualization. Based on Maslow's theory, job satisfaction has been approached by some researchers from the perspective of need fulfillment (Kuhlen, 1963; Worf, 1970; Conrad et al., 1985).

- Herzberg et al. (1959) formulated the two-factor theory of job satisfaction and postulated that satisfaction and dissatisfaction were two separate and sometimes even unrelated phenomena. Intrinsic factors named 'motivators' (that is, factors intrinsic to the nature and experience of doing work) were found to be job 'satisfiers' and included achievement, recognition, work itself and responsibility. Extrinsic factors which they named 'hygiene' factors were found to be job 'dissatisfiers' and included company policy, administration, supervision, salary, interpersonal relations and working conditions.

- Herzberg and Mausner's Motivation-Hygiene theory has dominated the study of the nature of job satisfaction, and formed a basis for the development of job satisfaction assessment. Thus job satisfaction is the affective orientation that an employee has towards his or her work (Price, 2001). It can be considered as a global feeling about the job or as a related constellation of attitudes about various aspects or facets of the job. The global approach is used when the overall attitude is of interest while the facet approach is used to explore which parts of the job produce satisfaction or dissatisfaction.

- Kennerly (1989) investigated the relationship among administrative leadership behaviors, organizational characteristics, and faculty job satisfaction in baccalaureate nursing programs of private liberal art colleges. The existence of organizational behaviors such as mutual trust, respect, certain warmth, and rapport between the dean/chair and the faculty member was a predictive factor in the development of nurse faculty job satisfaction.

- Billingsley and Cross (1992) studied 956 general and special educators in Virginia investigated commitment to teaching, intent to stay in teaching, and job satisfaction. Findings of this study revealed greater leadership 
support, work involvement, and lower levels of role conflict and stress-influenced job satisfaction for both groups studied.

- Moody (1996) reported a relationship between number of years teaching in the institution and satisfaction with the job, salary and coworkers.

- Spector (1997) has reviewed the most popular job satisfaction instruments and summarized the following facets of job satisfaction: appreciation, communication, co-workers, fringe benefits, job conditions, nature of the work itself, the nature of the organization itself, an organization's policies and procedures, pay, personal growth, promo promotion opportunities, recognition, security and supervision, Job satisfaction and its relating factors. He also felt that, the above approach has become less popular with increasing emphasis on cognitive processes rather than on underlying needs so that the attitudinal perspective has become predominant in the study of job satisfaction.

- Truell et al. (1998) stated that with limited studies regarding job satisfaction among faculty in community colleges, the study of job satisfaction is essential due tothe increasing number of student enrollments. Truell et al. (1998) found that faculty in their sample were more satisfied with the job itself.

- Doughty et al. (2002) studied Nurse Faculty at a small Liberal Arts College assessing perception of Nurse Faculty regarding their work environment. Factors most appreciated by faculty were involvement, coworker cohesion, supervisor support, and autonomy. This study showed that many factors contribute to job satisfaction of Nurse Faculty.

- Castillo and Cano (2004) conducted a study at an agricultural college at a large university by using the Herzberg's theory and the Wood Faculty Satisfaction/ Dissatisfaction Scale (WFSDS) to explore the factors that explain job satisfaction. Their findings showed that the work itself was the most important factor that

- contributed to job satisfaction, with working conditions being the least important. However, they did report that all of the factors of the Herzberg's theory were moderately related to job satisfaction. The increase in enrollment and the demands placed on faculty by the community, hospitals, and the college to produce a larger number of nursing graduates appears to be affecting morale and overall job Satisfaction.

- Hsiu-Chin et al. (2005, fourth quarter) findings were consistent with results of a study in Taiwan on Nurse Faculty job satisfaction and their perceptions of nursing deans' and directors' leadership styles. Findings revealed that Taiwanese Nurse Faculty is moderately satisfied with their jobs and that they preferred that their dean use a transformational type of leadership.

- Ambrose et al. (2005) conducted a qualitative study to investigate faculty satisfaction and retention. The study focused on the faculty of a private university over a period of 2 years. Findings suggested sources of satisfaction or dissatisfaction clustered into areas such as salaries, collegiality, mentoring, and the reappointment, promotion, and tenure process of departmental heads.

- Brady (2007) reported that many of the factors that affect nurse faculty in baccalaureate- and graduate degree nursing programs have a consequence on the retention of nurse faculty in associate-degree nursing programs as well. Various studies discussed shows that job satisfaction has been studied with relevance to co-worker behavior supervisor behavior, pay and promotion, organizational factors and other work related factors. In some studies the employees were highly satisfied or otherwise. Dominating studies in job satisfaction are available on nursing, teachers, doctors etc. But a study in banking sector is very rare. The gap in this literature is the negligible studies available in with special reference to banking sector employees that has motivated the researcher to find out the factors influencing employee job satisfaction in banking sector. Banking sector is a prime sector in the national scenario and mainly it has survived unaffected in spite of the recession.

\section{References}

[1] Ambrose S, Huston T, Norman M (2005). “A qualitative method for assessing faculty satisfaction”, Res. Higher Educ., 46(7): $803-830$.

[2] Billingsley B, Cross L (1992). "Predictors of commitment, job satisfaction, and intent to stay in teaching: A comparison of general and special educators", J. Special Educ. 25(4): 453-472.

[3] Brady M S (2007). "Recruitment and retention of associate degree nursing faculty", J. Nursing Educ., 46(4): 190-192.

[4] Castillo J, Cano J (2004). "Factors explaining job satisfaction among faculty", J. Agric. Educ., 45(3): 65-74.

[5] Cook, W. N. (1992) "Product Quality Improvement through Employee Participation: The Effects of Unionization and Joint UnionManagement Administration”. Industrial and Labour Relations Review, Vol. 46(1):119-134.

[6] Cotton, J. L., Vollrath, D. A. and Jenning, K. R. (1988) "Employee Participation: Diverse Forms and Different Outcomes". Academy of Management Review, Vol. 13(1):8-2

[7] Doughty J, May B, Butell S, Tong V (2002). "Work environment: A profile of the social climate of nursing faculty in an academic setting", Nursing Educ. Perspectives. 23(4): 191-196.

[8] Eaton, A. E. and Voos, P. A. (1992) "Unions and Contemporary Innovations in Work Organizations, Compensation and Employee Participation". Union and Economic Competitiveness, Armonk, New York: 173-215

[9] Gurin, G., Veroff, J., and Feld, S., (1960) Americans view their mental health. New York: Basic Books Herzberg F, Mausner B, Snyderman B B (1959). The motivation to work. New York Wiley. pp. 157. 
[10] Hsiu-Chin C, Beck S L, Amos L K (2005). Fourth Quarter): "Leadership styles and nursing faculty job satisfaction in Taiwan", J. Nursing Scholarship, 374: 380.

[11] Kanungo, R. N., (1979) The concepts of alienation and involvement revisited, Psychological Bulletin, 86, 119-38.

[12] Kennerly S M (1989). Leadership behavior and organizational characteristics: implications for faculty satisfaction", J. Nursing Educ.28: 198-202.

[13] Lammers, C. J. (1967) "Power and Participation in Decision-Making in Formal Organizations, American Journal of Sociology, Vol. 73(2):201-217.

[14] Locke, E. A. and Schweiger, D. M. (1979) "Participation in decision making: One more look", Research in Organizational Behavior, Vol. 1: 265-339.

[15] Lodahl, T. M., and Kejner, M., (1965) The definition and measurement of job involvement, Journal of Applied Psychology, 49, 2433.

[16] Maslow Abraham (1954). Motivation and Personality. New York: Harper. pp. 236.

[17] Mckelvey, B., and Sekaran, U., (1977) Toward a career-based theory of job involvement: A study of scientists and engineers, Administrative Science Quarter)\}', 22, 281-305.

[18] Mills, T. (1977) "Leadership from Abroad: European Development in Industrial Democracy", University of Notre dam press, London.

[19] Misra, S., and Kalro, A., (1981) Job involvement of intrinsically and extrinsically motivated Indian managers: To each according to his need, Human Relations, 34, 419-26.

[20] Moody N. B (1996). "Nurse faculty job satisfaction: a national survey", J. Professional Nursing, 12: $277-288$.

[21] Pateman, C. (1970) Participation and Democratic Theory, London: Cambridge University Press.

[22] Rabinowitz, S and Hall, D.T., (1977) Organization research on job involvement, Psychological Bulletin, 84, $265-88$.

[23] Truell A, Price W, Joyner R (1998). "Job satisfaction among community college occupational-technical faculty Community", College J. Res. Pract., 22(2), 111.

[24] Verma, A. (1995) Employee Involvement in the Workplace. Research in Personnel and Human Resource Management, New Haven, CT: JAI Press.

[25] Wagner, A. J. (1994) "Participation's Effects on Performance and Satisfaction: A Reconsideration of Research Evidence". Academy of Management Review, Vol. 19:312-3 